\title{
VARIABILIDADE PLUVIOMÉTRICA NA REGIÃO DO QUADRILÁTERO FERRÍFERO, MINAS GERAIS: ANÁLISE DA MÉDIA ANUAL DE PRECIPITAÇÃO DO PERÍODO DE 1991-2002
}

Flávio Henrique Nery ${ }^{1}$

\section{Resumo}

A presente pesquisa teve como objetivo analisar a variabilidade pluviométrica da região do quadrilátero ferrífero, assim como espacializar a distribuição da chuva e a sua possível correlação com o relevo a partir do comportamento pluviométrico. Através de análises e da caracterização do comportamento da pluviometria das séries históricas da Agência Nacional das Águas, período de 1991 a 2002, foi observado uma variação no regime pluviométrico da região. Esse segue um determinado padrão, apresentando maior pluviosidade em áreas específicas, devido, principalmente a influência das serras com maior altimetria. Os dados foram analisados utilizando estatística descritiva e geoestatística, por meio do método de Krigagem e Cokrigagem.

Palavras-chave:precipitação, quadrilátero ferrífero, geoestatística

\begin{abstract}
The presente study aims to analyze the rainfall variability on Iron Quadrangle region (Minas Gerais, Brazil) as well as the spatialization and distribution of rain and its possible correlation with relief based on rainfall behavior. Trough analysis and characterization of rainfall behavior in time series of National Water Agency, 1991 to 2002, we observed a variation on rainfall regime in the region. Following a particular pattern of rainfall, it was found the highest rainfall in specific areas, mainly due the influence of mountains with higher altimetry. Data has been analyzed using descriptive statistics and geoestatistics, by the Krigagem and Cokrigagem method.
\end{abstract}

Keywords:rainfall, iron quadrangle, geoestatistics

1Universidade Federal de Minas Gerais - UFMG/IGC - Av. Antônio Carlos, 6627 - 31270-901 - Belo Horizonte MG, Brasil

Cadernos do Leste

Artigos Cientificos

Belo Horizonte, Jan.-Dez. Vol.16, n¹6, 2016 


\section{1- INTRODUÇÃO}

A compreensão do comportamento da chuva num determinado local desempenha umimportante papel nas tomadas de decisão concernentes ao planejamento urbano e rural, afetando diretamente diversos setores sociais e econômicos. No caso específico de Minas Gerais, dentre todos os elementos climáticos que afetam o estado, a precipitação é aquela que mais prejuízo causa, tanto material quanto em perdas de vidas, principalmente, quando a chuva se concentra numa região densamente habitada.

Entretanto, o estudo da precipitação mostra-se como algo complexo, uma vez que os vezes, possibilitando a compreensão do processo somente após a ocorrência do episódio (NETO, 2003). Neste sentido, uma forma de buscar o entendimento deste fenômeno é o estudo da sua variabilidade, ou seja, análise dos registros efetuados num determinado período de tempo (séries temporais). O desafio que se coloca é o reconhecimento, com um grau mínimo de confiabilidade, da distribuição dos registros ao longo do tempo e a sua compreensão dos mecanismos que os definem (ZAVATTINE, 2013).

No quadrilátero ferrífero, por exemplo, o relevo apresenta-se como uma variável que deve ser considerada em qualquer análise sobre a dinâmica pluviométrica desta região. Segundo Iracema (2009), a topografia e a disposição do relevo são aspectos importantes para a compreensão das diversidades climáticas, onde a dinamização orográfica contribui localmente para os montantes pluviais.

A compreensão das relações espaciais dos dados coletados pelas estações pluviométricas e do relevo é possível por meio de um conjunto de técnicas de interpolação. Segundo Yamamoto e Landim (2013), uma forma possível é a aplicação da Cokrigagem, um procedimento geoestatístico onde é possível estimar diversas variáveis regionalizadas, desde que haja correlação entre a variável primária e as variáveis secundárias. É, portanto, uma extensão multivariada de estimativa que favorece a melhora das estimativas de amostragem de uma variável primária, como exemplo aquelas provenientes da krigagem ordinária (Fazio, 2013).

Desta forma, esse trabalho tem por objetivo analisar a variabilidade pluviométrica da região do quadrilátero ferrífero, assim como espacializar a distribuição da chuva e a sua possível correlação com o relevo através da aplicação de métodos estatísticos e de geoestatística. 


\section{2- LOCALIZAÇÃO}

O quadrilátero ferrífero localiza-se na porção centro-sudeste do estado de Minas Gerais (figura 01) e ocupa uma área aproximada de 900 ha (CODEMIG, 2005). A denominação desta região está associada à presença dos depósitos de minério de ferro, onde a sua formação corresponde a um bloco de estruturas do Pré-Cambriano (DORR, 1969). As rochas predominantes nas cristas são os quartzitos e itabiritos com altitudes entre 1300 a 2000 metros, neste contexto, destacam-se a Serra do Curral, a Serra da Moeda, Serra do Gandarela e a Serra do Caraça. No aspecto meteorológico, dentre os sistemas atmosféricos instáveis que atuam na área de estudo, destacam-se: Frentes Frias (FF), Zona de Convergência de Umidade (ZCOU), Linhas de Instabilidade (LI) e Zona de Convergência do Atlântico Sul (ZCAS) (ZAVATTINE, 2013).

Figura 01. Localização da área de estudo.

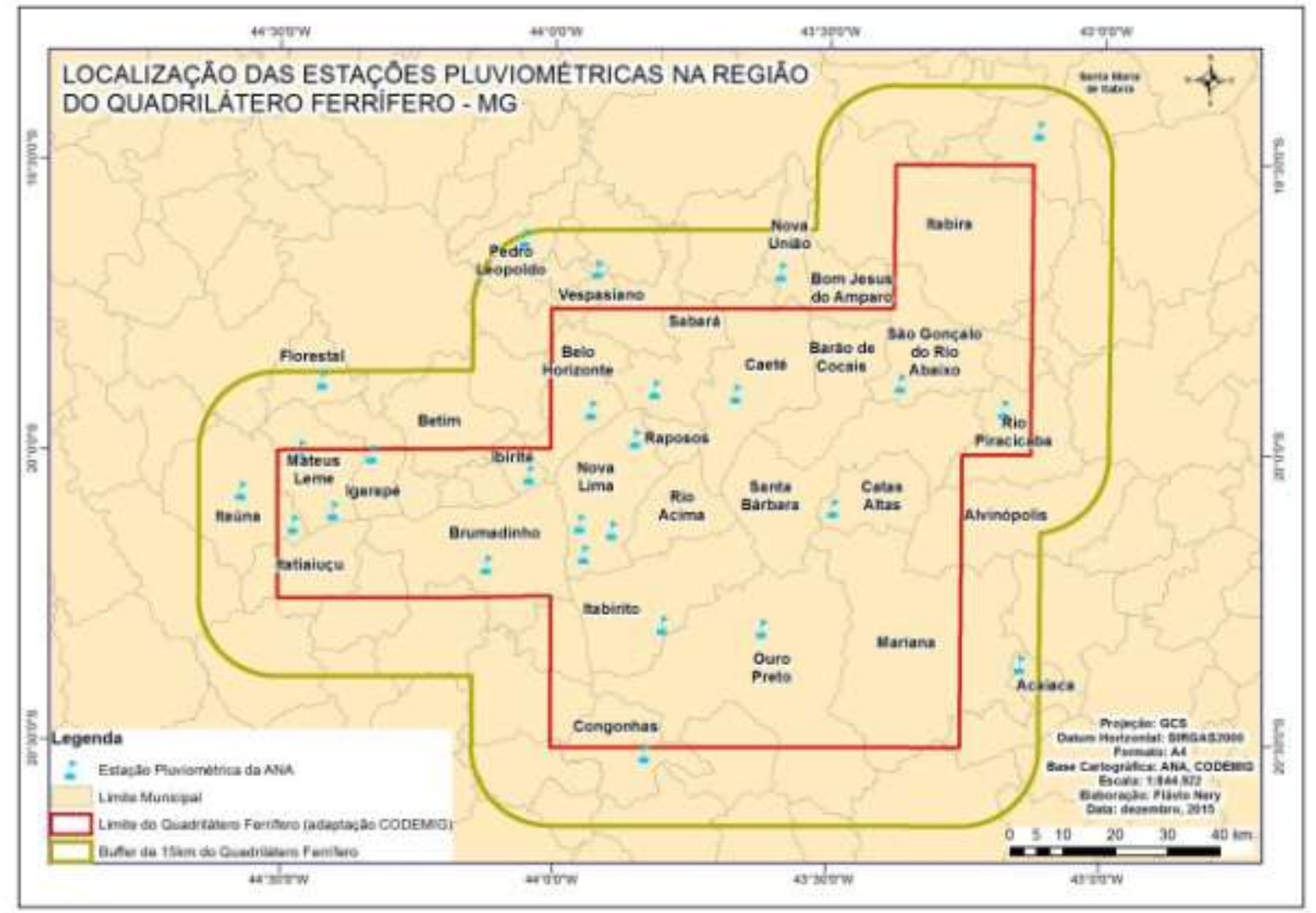

\section{3- MATERIAIS E MÉTODOS}

O levantamento dos registros de chuva na região do quadrilátero ferrífero se deu por meio dos dados pluviométricos consistidos da Rede Hidrometeorológica Nacional da Agência Nacional de Águas (ANA), onde, ao total, foram utilizadas 26 estações, sendo o período de dados correspondente à série histórica de 12 anos (1991 a 2002) (Tabela 01). O critério estabelecido para definição de quais estações seriam utilizadas foi à criação de um buffer de $15 \mathrm{~km}$ no entorno do Cadernos do Leste 
limite do quadrilátero ferrífero (adaptado do projeto Geologia do Quadrilátero Ferrífero Integração e Correção Cartográfica em SIG - CODEMIG) e a seleção das estações contidas nesse buffer. Além disso, foi realizada a triagem dos dados para identificação das séries históricas que apresentavam os dados mensais de precipitação de forma completa para o período determinado.

Para estudar a topografia local e sua consequente relação com a preciptação foram utilizadas as imagens da missão Shutte Radar Topographic Mission (SRTM) disponibilizadas e tratadas pela EMBRAPA (Projeto Brasil em Relevo). Os dados SRTM utilizados pertencem às cenas SF-23-X-A, SF-25-X-B, SF-23-Z-C e SF-25-Z-D, com 90 metros de resolução espacial, formato GEOTIFF, Sistema de Coordenadas Geográficas e Datum WGS- 84. Quanto às potencialidades dos dados SRTM, destaca-se que se trata da melhor informação disponibilizada sobre o território nacional, uma vez que as outras fontes disponíveis são generalistas (VALERIANO, 2004).

A aplicação das técnicas geoestatísticas foi precedida pela análise exploratória dos dados onde foram calculados valores de média, desvio padrão e coeficiente de variação e verificado tendenciosidades e valores discrepantes. Neste caso não foi considerado na geração dos modelos o fator tendência pelo fato de desconhecer a sua relação com a espacialização da chuva (Yamamoto e Landim, 2013).

Além disso, foi realizada a análise de correlação entre as variáveis relevo e precipitação sendo considerado o relevo como variável independente $(\mathrm{X})$ e a precipitação média anual como a variável dependente $(Y)$ sendo possível identificar se essas variáveis estavam correlacionadas e o grau dessa correlação. A análise de regressão também foi empregada de forma a possibilitar a compreensão do quanto a topografia pode explicar a distribuição pluviométrica em cada ano e, desse modo, enriquecer o modelo de distribuição espacial da precipitação pluviométrica quando incluídas.

Após essa etapa, os semivariogramas experimentais foram gerados e ajustados, considerando, além da variável primária (chuva intensa), uma variável secundária que, no caso deste estudo, foi aplicada à altitude das estações meteorológicas extraída do modelo digital de elevação, apresentado na figura 02.

Tabela 01. Localização das estações pluviométricas da Agência Nacional de Águas (ANA).

\begin{tabular}{|c|c|c|c|c|}
\hline Estação Pluviométrica & Munícipio & Latitude & Longitude & Altitude \\
\hline Acaiaca - Jusante & Acaiaca & $-20,3625$ & $-43,1439$ & 423,0 \\
\hline Alto da Boa Vista & Mateus Leme & $-20,1056$ & $-44,4011$ & 905,0 \\
\hline Belo Horizonte & Belo Horizonte & $-19,93$ & $-43,93$ & 915,0 \\
\hline
\end{tabular}

Cadernos do Leste

Artigos Cientificos

Belo Horizonte, Jan.-Dez. Vol.16, n¹6, 2016 


\begin{tabular}{|c|c|c|c|c|}
\hline Caeté & Caeté & $-19,9006$ & $-43,6675$ & 840,0 \\
\hline Colégio Caraça & Catas Altas & $-20,0969$ & $-43,4881$ & 1300,0 \\
\hline Congonhas - Linigrafo & Congonhas & $-20,5219$ & $-43,83$ & 871,0 \\
\hline Estiva & Mateus Leme & $-20,0003$ & $-44,4617$ & 806,8 \\
\hline Fazenda Água Limpa - Jusante & Ouro Preto & $-20,3053$ & $-43,6164$ & 965,0 \\
\hline Fazenda Coqueiros & Itaúna & $-20,1297$ & $-44,4744$ & 974,7 \\
\hline Fazenda Curralinho & Igarapé & $-20,0075$ & $-44,3311$ & 786,1 \\
\hline Fazenda Escola Florestal & Florestal & $-19,8797$ & $-44,4217$ & 745,0 \\
\hline Ibirité & Ibirité & $-20,0428$ & $-44,0433$ & 1073,0 \\
\hline Itabirito - Linigrafo & Itabirito & $-20,3011$ & $-43,7981$ & 885,0 \\
\hline Itaúna - Montante & Itaúna & $-20,0714$ & $-44,5703$ & 859,0 \\
\hline José de Melo & Nova União & $-19,6897$ & $-43,5856$ & 825,0 \\
\hline Lagoa Grande (MMV) & Nova Lima & $-20,1792$ & $-43,9428$ & 1350,0 \\
\hline Melo Franco & Brumadinho & $-20,1978$ & $-44,1208$ & 761,0 \\
\hline Mineração Morro Velho & Nova Lima & $-19,9792$ & $-43,85$ & 770,0 \\
\hline Pedro Leopoldo & Pedro Leopoldo & $-19,6344$ & $-44,0533$ & 698,0 \\
\hline Represa do Miguelão (MMV) & Nova Lima & $-20,1261$ & $-43,9503$ & 1152,0 \\
\hline Rio do Peixe (MMV) & Nova Lima & $-20,1378$ & $-43,8925$ & 1097,0 \\
\hline Rio Piracicaba & Rio Piracicaba & $-19,9228$ & $-43,1778$ & 623,0 \\
\hline Sabará & Sabará & $-19,8931$ & $-43,815$ & 720,0 \\
\hline Santa Maria de Itabira & Santa Maria de Itabira & $-19,4419$ & $-43,1178$ & 538,0 \\
\hline Usina Peti & $\begin{array}{l}\text { São Gonçalo do Rio } \\
\text { Abaixo }\end{array}$ & $-19,8808$ & $-43,3675$ & 1110,0 \\
\hline Vespasiano & Vespasiano & $-19,6872$ & $-43,9208$ & 676,0 \\
\hline
\end{tabular}

A geração dos cartogramas com a precipitação anual acumulada para o período de 1991 a 2002 foram executados pelo software ArcGIS 10.3.1 através da ferramenta Geostatistical Analyst. Os interpoladores Krigagem e Co-Krigagem, presentes nessa ferramenta, foram testados de forma a identificar qual o interpolador representa melhor a variabilidade de chuvas nessa região.

Figura 02. Altimetria do Quadrilátero Ferrífero. 


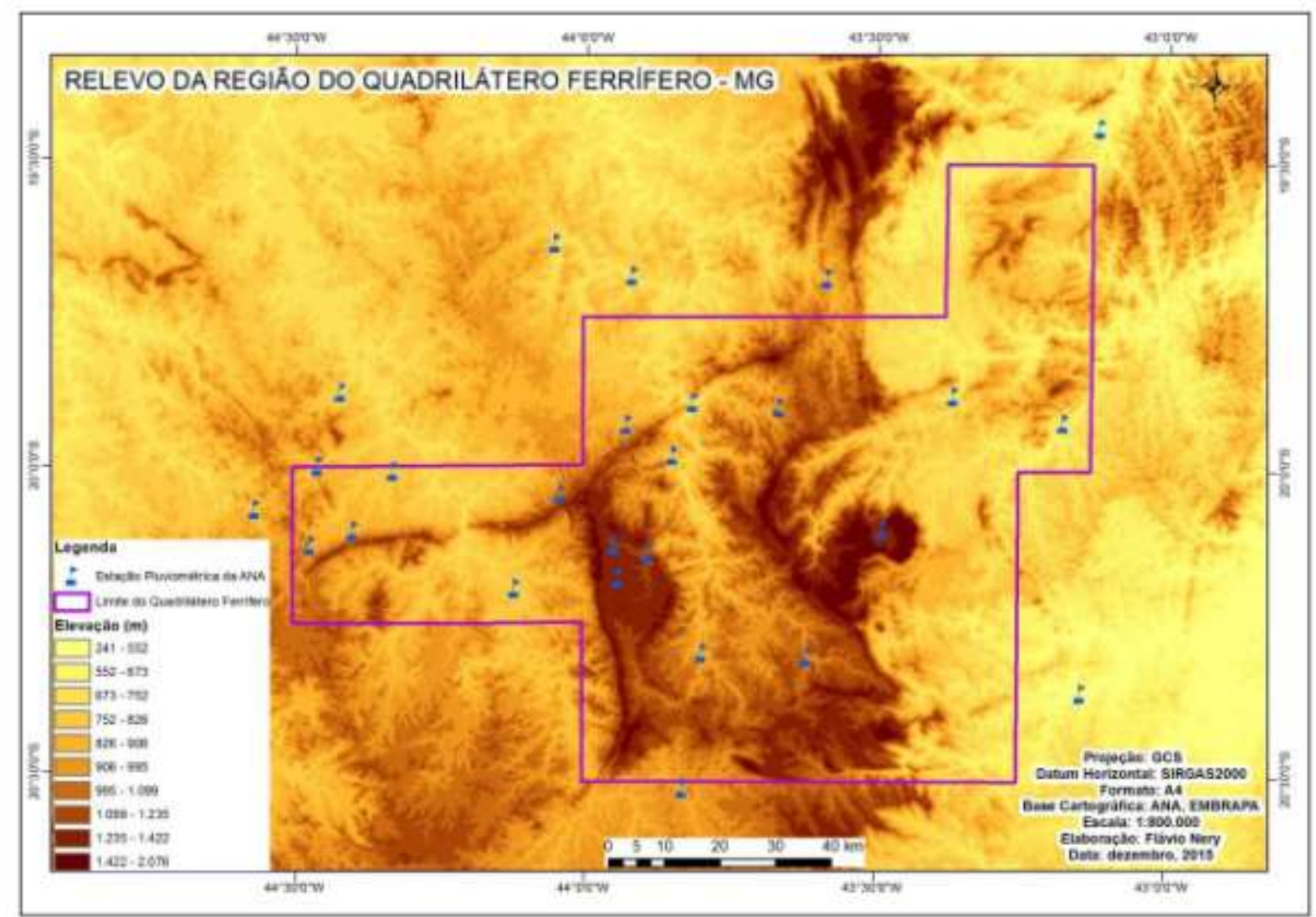

\section{4- RESULTADOS E DISCUSSÃO}

As 26 estações pluviométricas apresentaram um valor médio anual de precipitação de $1.491,4 \mathrm{~mm}$, com desvio padrão de aproximadamente $133 \mathrm{~mm}$ e coeficiente de variação de 8,1\%. O gráfico 01 demostra a variação do volume de chuva por estação com seu respectivo coeficiente de variação. Destaca-se a estação colégio caraça, com média anual de 1.850,2 mm, e Santa Maria do Itabira com média anual de 1.247,1 mm.

$\mathrm{Na}$ análise do coeficiente de variação, observamos, quanto menor o valor, mais preciso são os dados. Apesar disso, segundo Yamamoto e Landim (2013), valores abaixo de 25\% são considerados baixos, ou seja, apresentam dados mais homogêneos e consistentes.

Observando o gráfico 02 , temos a relação média de precipitação por ano, onde os anos de 1991, 1992 e 1993 apresentaram os maiores coeficientes de variação, sendo 15,96\%, 15,57\% e 16,92\%, respectivamente. Com isso, estes dados apresentaram maior variação em torno da média.

Gráfico 01. Precipitação média em cada estação analisada.

Cadernos do Leste

Artigos Cientificos

Belo Horizonte, Jan.-Dez. Vol.16, n¹6, 2016 


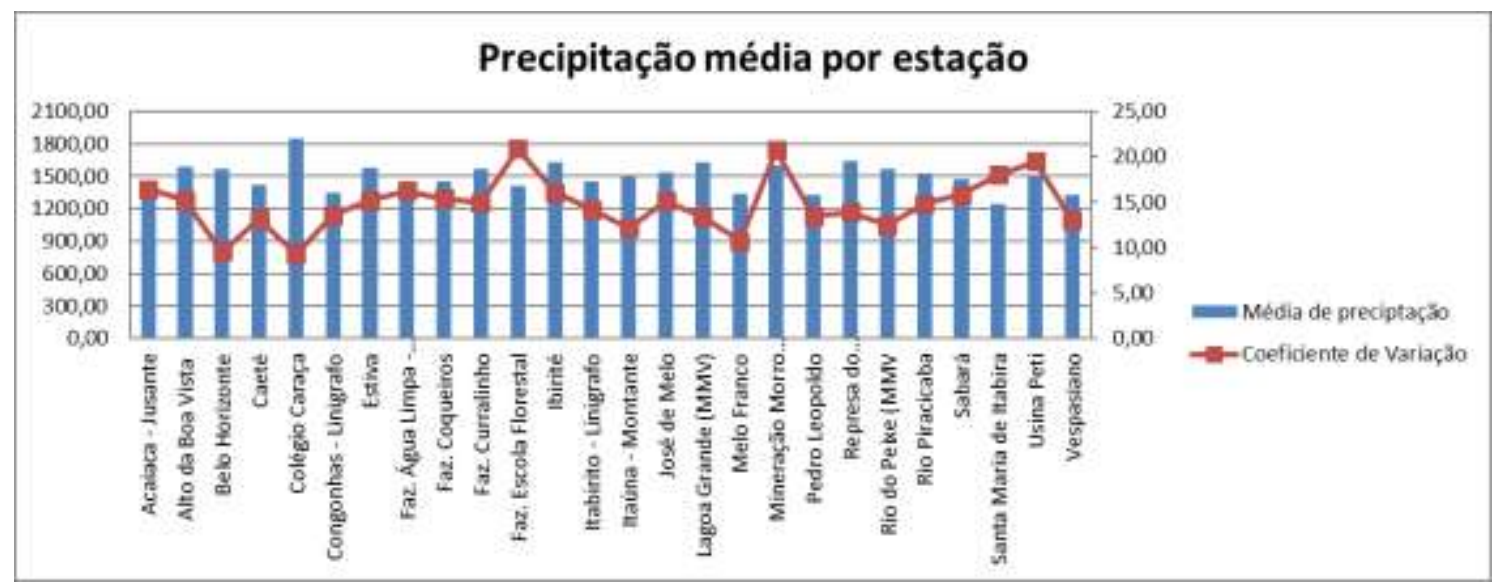

Gráfico 02. Precipitação média por ano.

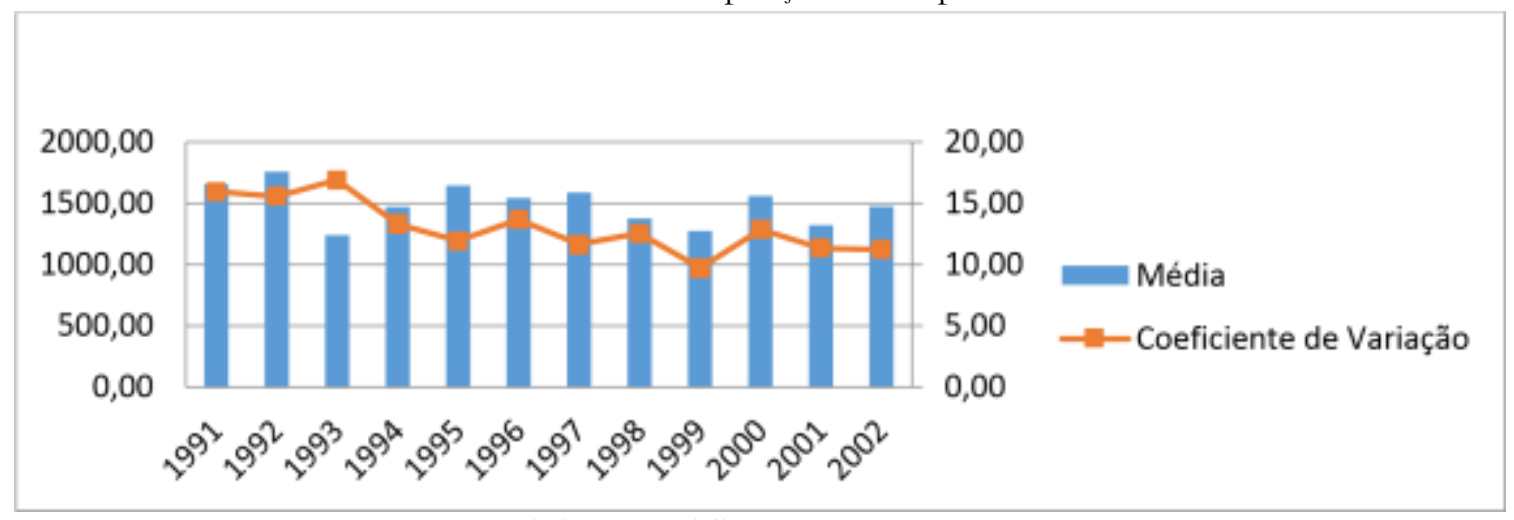

Precipitação média por ano (1991-2002)

É possível notar que anos com menor volume pluviométrico via de regra têm os maiores coeficientes de variação, ou seja, há maior heterogeneidade intra-anual nos anos menos chuvosos. O oposto também ocorre, o que significa que os anos mais chuvosos, no caso, apresentaram essa tendência ao longo de todo o ano.

$\mathrm{Na}$ correlação entre precipitação e relevo, foi inserido o gráfico sobre o comportamento da chuva para compreender a sua dinâmica neste período. Para Cohen (1988), valores entre 0,10 e 0,29 podem ser considerados pequenos; escores entre 0,30 e 0,49 podem ser considerados como médios; e valores entre 0,50 e 1 podem ser interpretados como grandes.

No gráfico 03, o coeficiente $\mathrm{R}^{2}$ mede o grau de relacionamento linear entre os valores emparelhados X e Y na mostra, com isso a variável relevo explica 45\% da variável precipitação. Temos ainda uma relação linear positiva com o coeficiente de correlação de 0,67. Com a existência de correlação entre as duas amostras, isto valida a interpolação de dados pelo método de cokrigagem para refinamento da espacialização da chuva com base no relevo.

Gráfico 03. Análise de correlação entre precipitação média anual e a altimetria.

Cadernos do Leste 


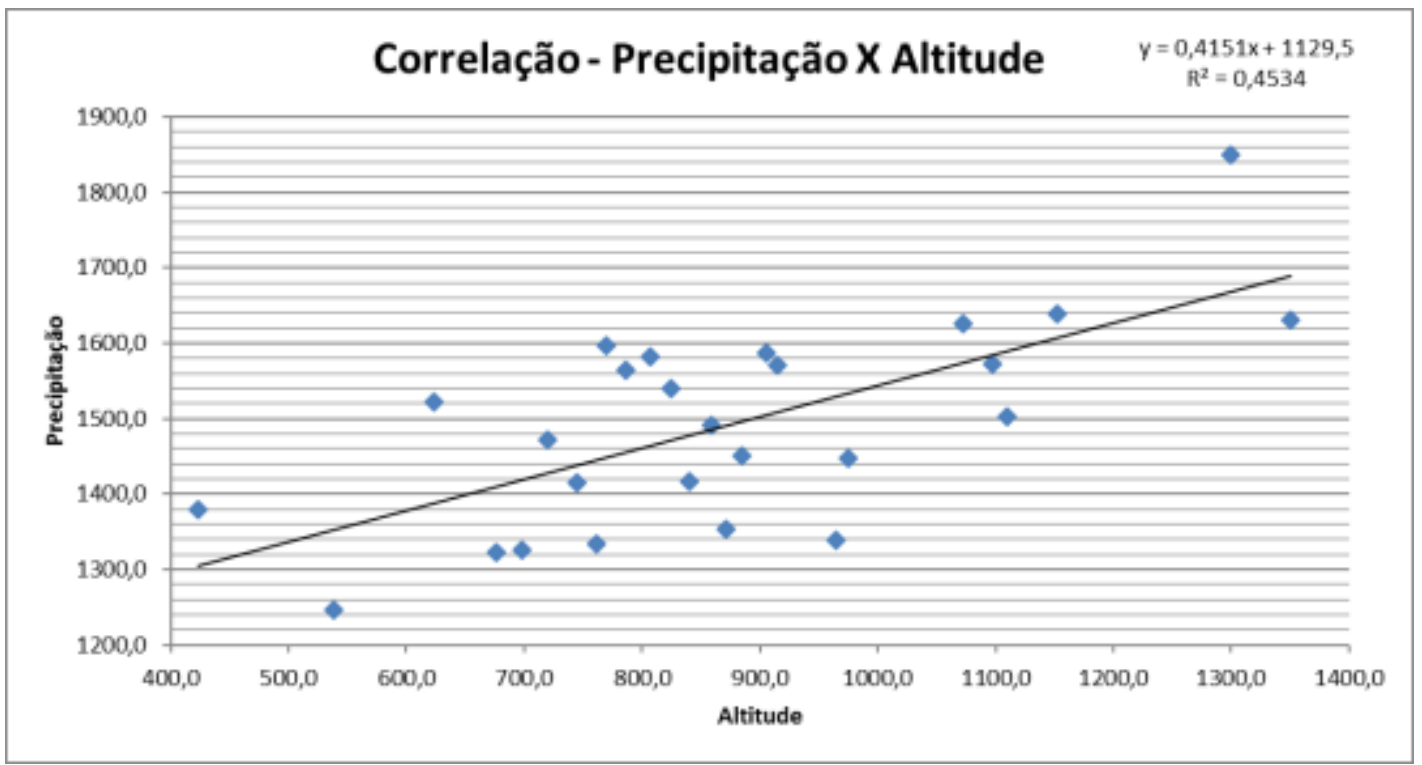

$\mathrm{Na}$ análise geoestatística observou-se a dependência espacial do fenômeno estudado por meio do semivariogramas experimental, onde ficou constatado a anisotropia nas estações pluviométricas. O ajuste do modelo spherical foi testado e os erros estatísticos cruzados para comparar o resultado da krigagem com a cokrigagem (tabela 02).

Tabela 02. Erros de prognóstico da interpolação.

\begin{tabular}{|c|c|c|}
\hline Erros do prognóstico & Krigagem & Cokrigagem \\
\hline Samples & 26 de 26 & 26 de 26 \\
\hline Mean & 20,11 & 10,86 \\
\hline Root-Mean-Square & 126,61 & 122,67 \\
\hline Mean Standardized & 0,12 & 0,03 \\
\hline Root-Mean-Square-Standardized & 1,05 & 1,03 \\
\hline Average Standard Error & 111,01 & 110,69 \\
\hline
\end{tabular}

Desta forma, a cokrigagem apresentou um melhor ajuste para a precipitação média anual. Apesar disto, os dois métodos apresentaram elevados erros médios padrão (Krigagem - 111,01 e cokrigagem - 110,69), provavelmente associado a ausência de uma melhor distribuição das estações pluviométricas na região do quadrilátero ferrífero. Apesar disto, os erros não são superiores a $10 \%$ da média histórica das estações estudadas.

Portanto, foram elaborados os dois mapas correspondente aos métodos de krigagem e cokrigagem. O mapa da krigagem (figura 03) apresentou as isolinhas mais suavizadas e favoreceu o aparecimento de círculos concêntricos, sendo o resultado mais generalista. Já o mapa da Cadernos do Leste 
cokrigagem (figura 04) apresentou um desenho mais recortado, devido a orientação do relevo local.

Em ambos fica nítido a orientação da precipitação pela altimetria. A maior concentração de chuva está localizada na Serra do Caraça e entorno, com registro de 1.850,2 mm e a também o ponto mais alto do quadrilátero com aproximadamente 2.000 metros. Deste a faixa se estende em duas direções, ao norte sentido Serra do Espinhaço e à oeste sentido Serra do Curral e Serra da Moeda.

Figura 03. Precipitação média anual utilizando krigagem.

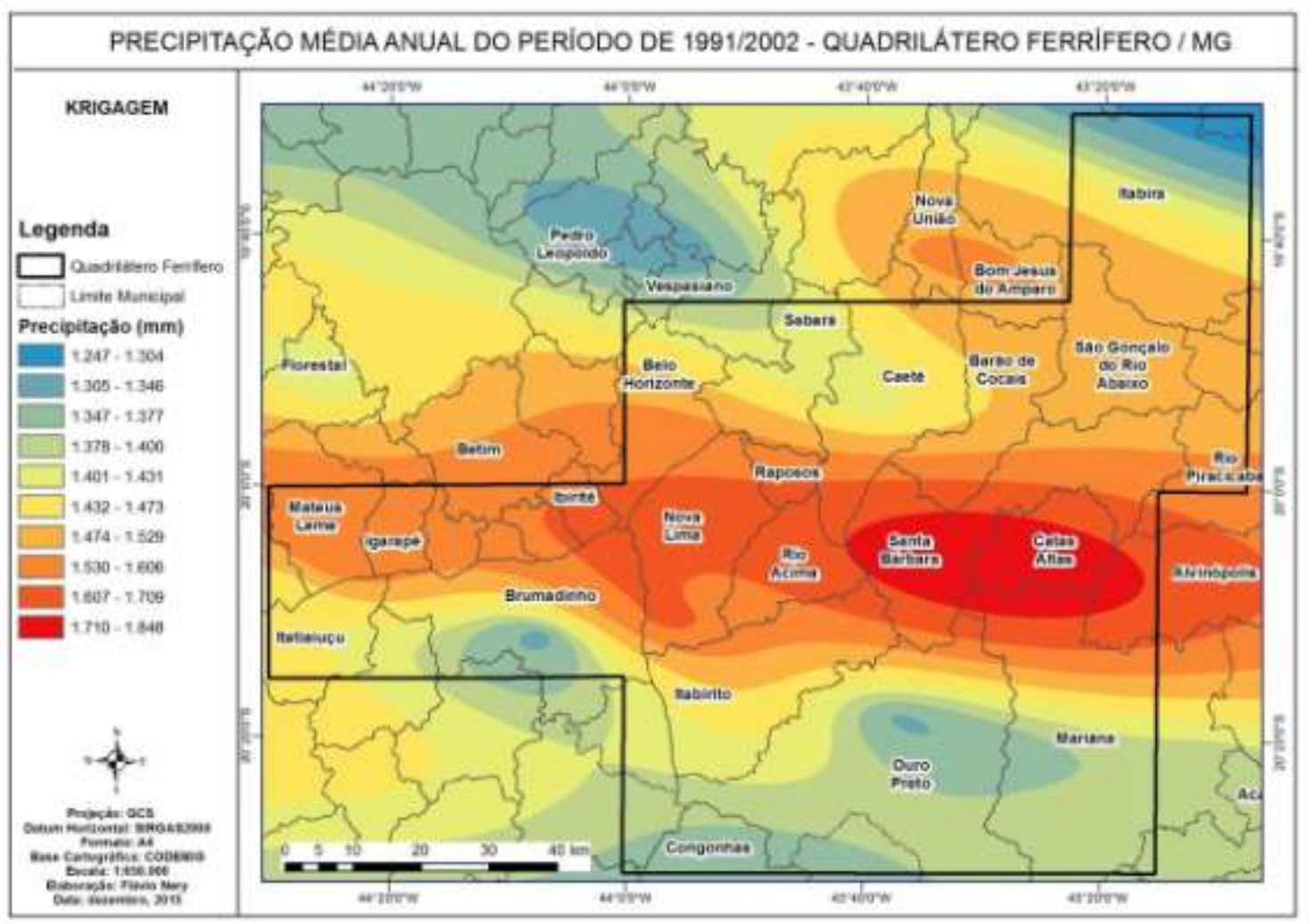

Figura 04. Precipitação média anual utilizando cokrigagem.

Cadernos do Leste 


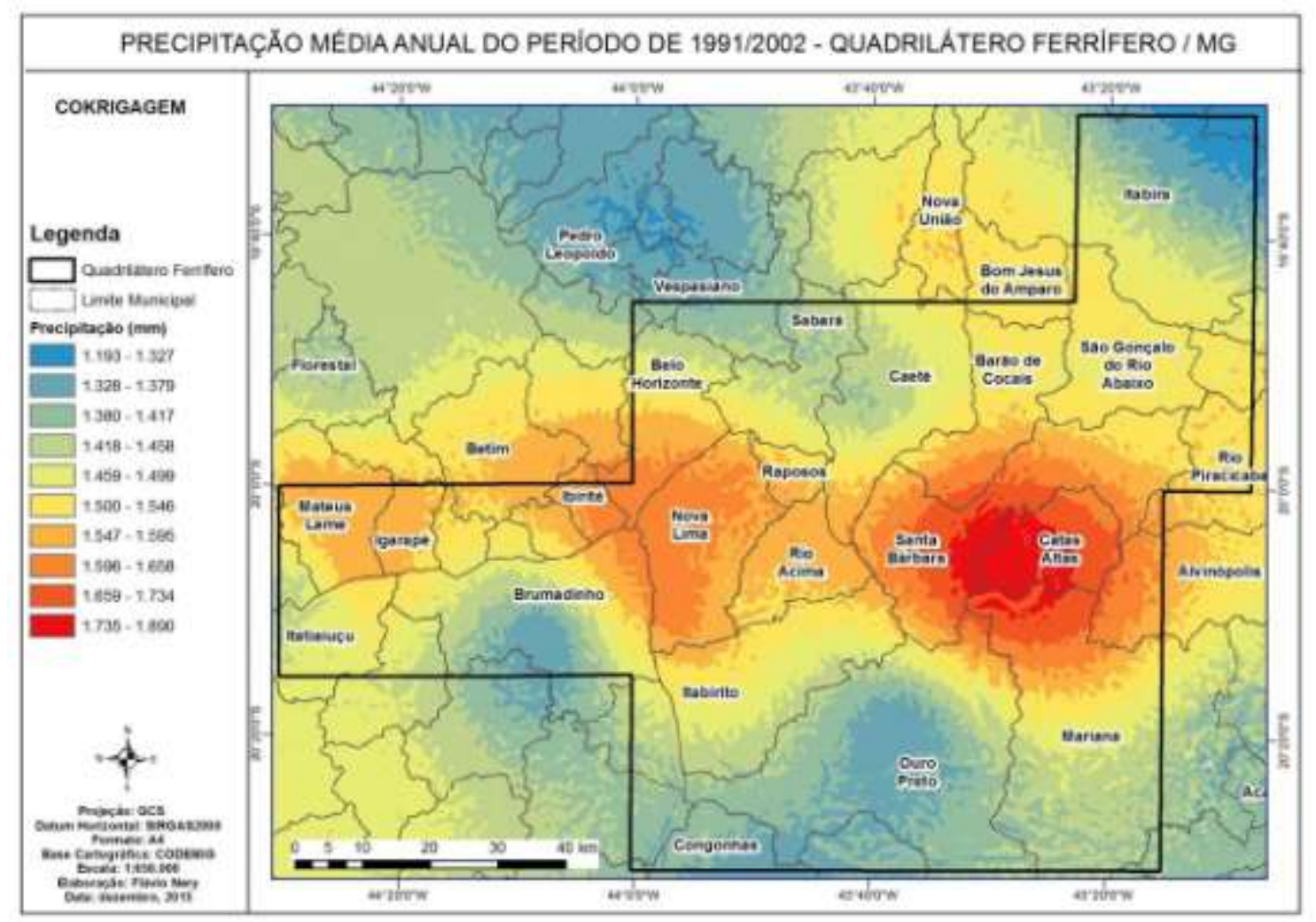

\section{CONSIDERAÇÕES FINAIS}

A falta de um maior número de estações pluviométricas melhor distribuídas na região do quadrilátero ferrífero é um obstáculo para um trabalho que envolva interpolação matemática. Além disto, as lacunas existentes nas séries históricas prejudicam o estudo de séries maiores, necessitando realizar ponderações para o seu preenchimento.

Através dos resultados podemos levantar algumas considerações sobre a dinâmica da precipitação no quadrilátero ferrífero. Ficou nítido a influência do relevo sobre distribuição espacial com destaque para a Serra do Caraça, Serra do Curral e Serra da Moeda. Há necessidade de estudos de clima nesta região, devido as poucas referencias encontradas na literatura.

\section{REFERÊNCIAS BIBLIOGRÁFICAS}

CODEMIG. Programa de Mapeamento Geológico - Quadrilátero Ferrífero. Belo Horizonte: Embrapa Monitoramento por Satélite, 2005. Disponível em: <http://www.codemig.com.br>. Acesso em: 16 nov. 2015.

COHEN, Jacob. (1988), Statistical power analysis for the behavioral sciences. Hillsdale, NJ, Erlbaum

DORR, J. V. N. Physiographic, stratigraphic and structural development of Quadrilátero Ferrífero, Minas Gerais, Brazil. Geological Survey Professional Paper 641-A. USGS/DNPM, 1969. 
FAZIO, V. S. Interpolação Espacial: uma comparação analítica entre redes RBF e Krigagem. Florianópolis: Oficina de Textos, 2013.

IRACEMA F. A. C. (Org.). Tempo e clima no Brasil. São Paulo: Oficina do Texto, 2009.

MIRANDA, E. E. de; (Org.). Brasil em Relevo. Campinas: Embrapa Monitoramento por Satélite, 2005. Disponível em: <http://www.relevobr.cnpm.embrapa.br>. Acesso em: 11 nov. 2015.

NETO, J. L. S. Da complexidade física do universo ao cotidiano da sociedade: mudança, variabilidade e ritmo climático. Revista Terra Livre, São Paulo, v. I, n. 20, p. 51-63, jan/jul. 2003.

VALERIANO, M. M. Curvatura vertical de vertentes em microbacias pela análise de modelos digitais de elevação. Revista Brasileira de Engenharia Agrícola e Ambiental, v. 7, n. 3, pp. 539546, 2003.

YAMAMOTO, J. K.; LANDIM, P. M. B. Geoestatística: conceitos e aplicações. São Paulo: Oficina de Textos, 2013.

ZAVATTINI, J. A.; Boin, M. N. Climatologia geográfica: teoria e prática de pesquisa. Campinas, SP: Editora Alínea, 2013. 